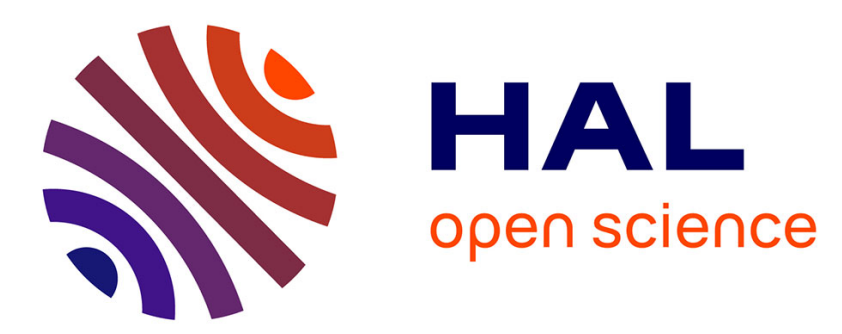

\title{
Substituent Effects in Carbon-Nanotube-Supported Copper Phenolato Complexes for Oxygen Reduction Reaction
}

Solène Gentil, Jennifer K. Molloy, Marie Carrière, Gisèle Gellon, Christian Philouze, Doti Serre, Fabrice Thomas, Alan Le Goff

\section{To cite this version:}

Solène Gentil, Jennifer K. Molloy, Marie Carrière, Gisèle Gellon, Christian Philouze, et al.. Substituent Effects in Carbon-Nanotube-Supported Copper Phenolato Complexes for Oxygen Reduction Reaction. Inorganic Chemistry, 2021, 60 (10), pp.6922-6929. 10.1021/acs.inorgchem.1c00157 . hal-03269138

\section{HAL Id: hal-03269138 \\ https://hal.science/hal-03269138}

Submitted on 14 Oct 2021

HAL is a multi-disciplinary open access archive for the deposit and dissemination of scientific research documents, whether they are published or not. The documents may come from teaching and research institutions in France or abroad, or from public or private research centers.
L'archive ouverte pluridisciplinaire HAL, est destinée au dépôt et à la diffusion de documents scientifiques de niveau recherche, publiés ou non, émanant des établissements d'enseignement et de recherche français ou étrangers, des laboratoires publics ou privés. 


\section{Substituent effects in Carbon-Nanotube-supported}

\section{copper-phenolato complexes for Oxygen Reduction}

\section{Reaction}

Solène Gentil, Jennifer K. Molloy, Marie Carrière, Gisèle Gellon, Christian Philouze, Doti

Serre, Fabrice Thomas, Alan Le Goff

\section{To cite this version:}

Gentil, Solène, Jennifer K. Molloy, Marie Carrière, Gisèle Gellon, Christian Philouze, Doti Serre, Fabrice Thomas, et Alan Le Goff. «Substituent Effects in Carbon-Nanotube-Supported Copper Phenolato Complexes for Oxygen Reduction Reaction ». Inorganic Chemistry 60, ${ }^{\circ} 10$ (17 mai 2021): 6922-29. https://doi.org/10.1021/acs.inorgchem.1c00157. hal-03269138 


\section{Substituent effects in Carbon-Nanotube-supported}

\section{copper-phenolato complexes for Oxygen Reduction}

\section{Reaction}

Solène Gentil, [a,b] Jennifer K. Molloy, [a] Marie Carrière, [c] Gisèle Gellon, [a] Christian

Philouze [a], Doti Serre, [a], Fabrice Thomas, *[a] and Alan Le Goff* [a]

[a] Univ. Grenoble Alpes, CNRS, DCM, 38000 Grenoble, France

E-mail: alan.le-goff@univ-grenoble-alpes.fr, fabrice.thomas@univ-grenoble-alpes.fr,

[b] Univ. Grenoble Alpes, CEA, CNRS, Laboratoire de Chimie et Biologie des Métaux, 38000 Grenoble, France

KEYWORDS copper complexes, oxygen reduction, carbon nanotubes, bioinspired catalysts, fuel cells

ABSTRACT Unprotected mononuclear PMP-pyrene copper complexes were designed to be immobilized at multi-walled carbon nanotube (MWCNT) electrodes and form dinuclear bis $(\mu-$ phenolato) complexes on surface. These complexes exhibit high ORR activity of $12.7 \mathrm{~mA} \mathrm{~cm}^{-2}$ and onset potentials of $0.78 \mathrm{~V}$ vs. RHE. The higher activity of these complexes, as compared to mononuclear complexes with bulkier groups, is induced by the favorable early formation of a dinuclear catalytic specie on MWCNT. 
Achieving oxygen reduction reaction (ORR) without using precious metal catalysts is of tremendous importance to develop fuel cells on an industrial scale. Platinum still remains the stateof-the-art catalyst able to perform the challenging four electron /four proton oxygen reduction to water at low overpotential in proton-exchange Membrane Fuel cells (PEMFCs). ${ }^{1,2}$ In Nature, the four-proton/four electron ORR is perfectly achieved at the trinuclear copper cluster of multicopper oxidases such as laccases or bilirubin oxidases. ${ }^{3-5}$ When favorably immobilized at electrodes, these enzymes performs ORR at similar overpotential as compared to $\mathrm{Pt}^{6-8}$. However, such fragile catalysts are not meant to be integrated in PEMFCs. This have driven molecular chemists to mimick these multicopper active sites to achieve low overpotential $\mathrm{ORR}^{9-13}$. We and other have particularly investigated the immobilization of these bioinspired catalysts at electrode surfaces in order to achieve ORR in water. ${ }^{13-18}$ In particular, carbon-nanotube (CNT)-based electrodes are highly conductive, provide ease of functionalization strategies to immobilize redox molecules, and allows the integration of molecular catalysts in functional devices. ${ }^{19-23}$ However, only few copper complexes have shown ORR activity at acidic $\mathrm{pHs}$, a prerequisite for their integration in PEMFCs where a proton-exchange membrane such as Nafion is used. ${ }^{10,13,16,24-26}$ In this regard, most examples of mononuclear and dinuclear copper complexes have shown the importance of the presence of at least two copper centers to achieve efficient ORR. ${ }^{13,17,27}$ The dicopper catalytic intermediate has been either introduced via ligand design or has been either formed on the electrode surface during $\mathrm{O}_{2}$ activation. In this respect, we recently designed mono- ${ }^{18}$ and dicopper-phenolato ${ }^{19}$ complexes based on pyrene-modified (bispyridylaminomethyl)methylphenol (PMP-pyrene) tripodal ligands. These complexes, bioinspired by the active site of galactose 
oxidase and tyrosinase, were immobilized at Multi-walled CNT (MWCNT) electrodes owing to the pi-pi-stacking interaction of a pyrene moiety, introduced in the ligand, with MWCNT sidewalls. These functionalized nanostructured hybrid electrodes achieved close performances towards ORR, suggesting the participation of two copper centres in both the mononuclear and dinuclear species.

In order to further progress in the understanding of this multicopper ORR catalyst family, we turned, in this work, to unprotected mononuclear PMP-pyrene copper complexes, prone to form dinuclear intermediates. Herein, we describe a new family of dicopper complexes immobilized at the surface of Multi-Walled CNT (MWCNT) electrodes. We previously observed that the PMP ligand without bulky groups at the ortho position of the phenol ring is prone to form dinuclear specie with a bisphenolate $\mathrm{Cu}_{2} \mathrm{~N}_{2} \mathrm{O}_{2}$ core in solution. ${ }^{28}$ These dimers, based on pyrene ligands, are derived from the previously-described $\mathbf{M e P M} \mathbf{P}^{\mathbf{B} u}$-pyrene tripodal ligand. ${ }^{18} \mathrm{We}$ decided to decrease the steric bulk in the phenolic ortho position in order to favor dimerization of copper complexes by formation of a favorable phenolate/oxo bridge known to be involved in the catalytic mechanism of many mono and dinuclear copper complexes. We herein describe these complexes based on the HPMP-pyrene and MePMP-pyrene ligands (Scheme 1). Furthermore, we compare them with the mononuclear derivative $\mathbf{C F}_{3} \mathbf{P} \mathbf{M P}^{\mathbf{t B u}}$-pyrene in which a $\mathrm{CF}_{3}$ was introduced in order to shift redox potentials of this series towards more positive potentials. 


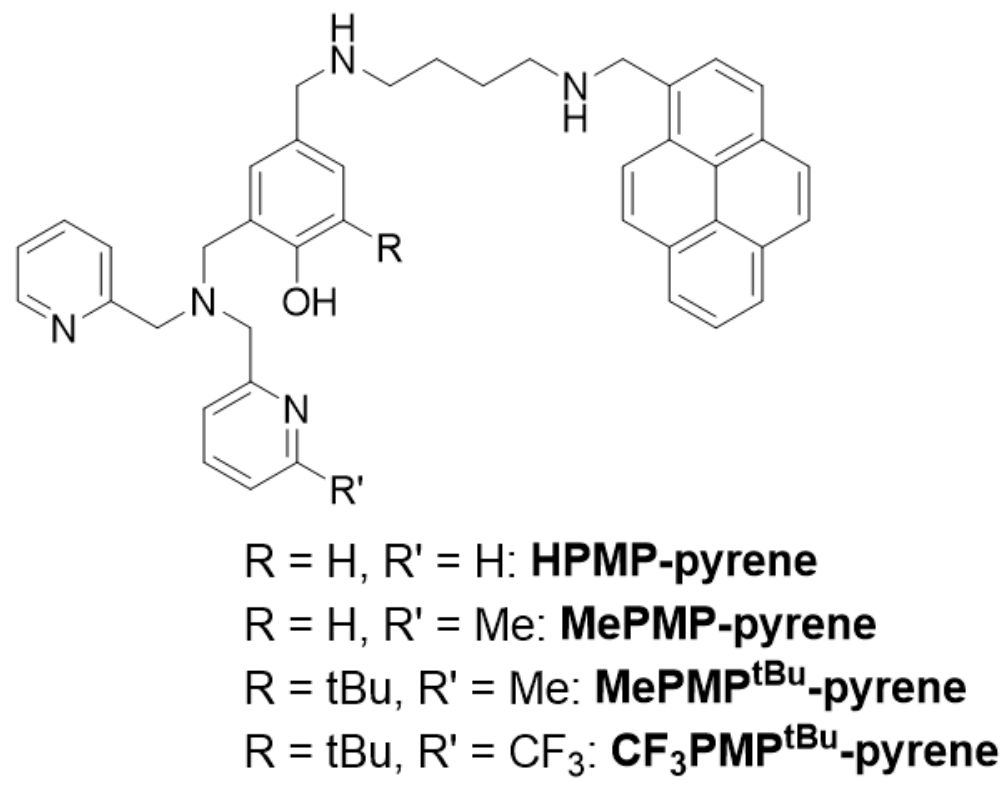

Scheme 1. Structures of the ligands

The complexes strongly interact with the CNT sidewalls owing to well-characterized $\pi-\pi$ interactions between pyrene groups and the pi-extended network of CNT walls. Their electrochemical characterization, as well as their ORR activity are presented.

The ligands HPMP-pyrene, MePMP-pyrene and CF3PMP ${ }^{\text {Bu }}$-pyrene were prepared in a similar way than the previously reported MePMP ${ }^{\text {tBu}}$-pyrene (see ESI). ${ }^{18}$ The synthesis is based on the reductive amination of the aldehyde tripod precursor by a pyrene-putrescine conjugate. The copper complexes were formed upon reaction of the ligand with one molar equivalent of copper(II) salt. The speciation of the in situ generated copper complexes was investigated by $\mathrm{pH}$ titrations in the $\mathrm{pH}_{\mathrm{s}}$ range 2-7, with $\mathrm{UV}-\mathrm{V}$ is monitoring (detailed spectral properties are listed in Table S1) ${ }^{29}$. At $\mathrm{pHs}$ close to 2 the complexes appear blue, with a visible spectrum that mainly displays a low 
intensity band (ca.650 nm) assigned to copper(II) d-d transitions. No significant substituent effect was detected, confirming a similar environment around the copper. Increasing the pHs results in the growing of a higher intensity band at ca. $440 \mathrm{~nm}$, with precipitation above ca. $\mathrm{pHs}=6$. Refinement of the titration data points to an $\varepsilon$ value larger than $300 \mathrm{M}^{-1} \mathrm{~cm}^{-1}$ for this more intense band, which supports its assignment as phenolate-to-copper charge transfer (CT) transition. The corresponding phenol's pKa, was estimated to $4.3 \pm 0.3$ and $4.9 \pm 0.3$ for [Cu(MePMP-pyrene)] and [Cu(HPMP-pyrene)], respectively. Here the large standard deviation resulting from early precipitation does not allow for a clear appreciation of the substituent effect. This pKa value is however significantly higher than for the dinuclear [C $\mathbf{U u}_{2}$ (BPMP-pyrene)],${ }^{19}$ suggesting a less electropositive environment around the phenolic oxygen (coordination to one instead of two copper ions). For $\left[\mathbf{C u}\left(\mathbf{C F}_{3} \mathbf{P M P}^{\mathrm{tBu}}\right.\right.$-pyrene $\left.)\right]$ the pKa was found to be remarkably lower $(2.41 \pm 0.04)$ than for $\left[\mathbf{C u}\left(\mathbf{M e P M P} \mathbf{P}^{\mathrm{tBu}}\right.\right.$-pyrene)] due to the strong electron withdrawing effect of the $\mathrm{CF}_{3}$ group.

The EPR spectra recorded at $\mathrm{pH}_{\mathrm{s}}<\mathrm{pKa}-1$ and $>\mathrm{pKa}+1$ both display the features of an $(S=$ 1/2) system with copper hyperfine splitting. ${ }^{30}$ Double integration of the signal confirms, within the accuracy of EPR $(\approx 10 \%)$ the mononuclear nature of the complexes under both their phenol and phenolate forms. This behaviour is reminiscent of copper(II) complexes of tripodal ligands in aqueous medium, ${ }^{28}$ whereby a water molecule completes the coordination polyhedron in order to achieve a mononuclear square pyramidal geometry. It must be emphasized at this point that hydrophobic phenolate derivatives assemble as dimers in the solid state and concentrated or noncoordinating organic solvents. ${ }^{28,31}$ Hence despite the observation of monomers in diluted aqueous medium, the formation of dimers under other conditions cannot be ruled out. 


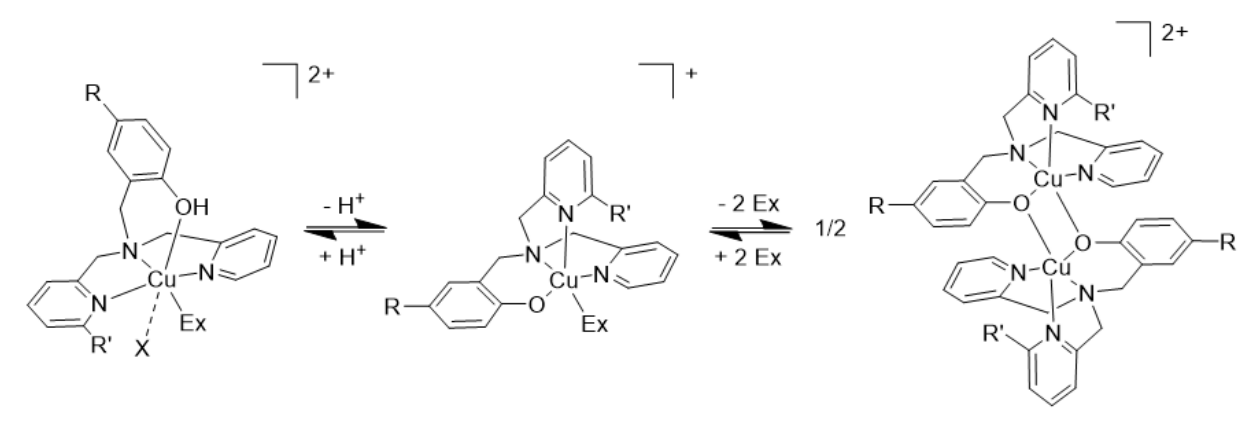

Scheme 2. Protonation and dimerization equilibria of the complexes $(E x=$ exogenous solvent, $X$ $=$ counter-ion, $\mathrm{R}=\mathrm{CHO}$ or putrescine-pyrene chain, $\mathrm{R}^{\prime}=\mathrm{H}$ or $\left.\mathrm{Me}\right)$

In order to confirm this hypothesis, we conducted crystallization assays of the copper complexes both in the presence of base or not. Crystallization of the pyrene appended complexes was not successful, presumably due to the flexibility of the putrescine linker, but crystals were isolated from the aldehyde precursors (in these precursors the aldehyde function replaces the pyreneputrescine chain). The X-Ray crystal structures are depicted in Fig. 1 for three representative complexes. Complex $\left[\mathbf{C u}(\mathbf{H P M P}-\mathbf{C H O})\left(\mathbf{C H}_{3} \mathbf{C N}\right)\right]^{2+}$ was prepared from $\left[\mathrm{Cu}\left(\mathrm{ClO}_{4}\right)_{2}\right] .6 \mathrm{H}_{2} \mathrm{O}$ in $\mathrm{CH}_{3} \mathrm{CN}$ and crystallized by slow diffusion of diethyl ether. This blue complex (color associated to d-d transitions) is mononuclear and comprises a phenol unit whereby the oxygen atom weakly binds in the apical position (Cu-O1 bond distance of $2.500 \AA$ ) of a Jahn-Teller distorted octahedral copper ion. The opposite position is occupied by a perchlorate counter-ion coming from the copper salt, again weakly bound (Cu-O2 bond distance of $2.472 \AA$ ). The equatorial plane is defined by the tertiary amine, two pyridines and one exogenous acetonitrile molecule, with $\mathrm{Cu}-\mathrm{N}$ bond distances in the $1.980-2.031 \AA$ range. In the presence of triethylamine dark green crystals of 
$\left[\mathrm{Cu}_{2}(\mathrm{HPMP}-\mathrm{CHO})_{2}\right]^{2+}$ were obtained (color due to the phenolate-to-copper CT transition). X-Ray diffraction reveals a dimeric complex wherein the two copper centers $\mathrm{Cu}$ and $\mathrm{Cu}$ ' are bridged by two $\mu$-phenolate units. The copper ion is pentacoordinated, with two $\mu$-phenolato oxygens $\mathrm{O} 1$ and $\mathrm{O}^{\prime}$ ' and three $\mathrm{N}$ atoms for the pyridines and the tertiary amine. The geometry is intermediate between square pyramidal (with one apical $\mu$-phenolate oxygen donor) and trigonal bipyramidal, as demonstrated by a tau index of $0.37 .{ }^{32}$ As expected the $\mathrm{Cu}-\mathrm{O} 1$ and $\mathrm{Cu}-\mathrm{O} 1$ ' bond distances are shorter than in $\left[\mathbf{C u}(\mathbf{H P M P}-\mathbf{C H O})\left(\mathbf{C H}_{3} \mathbf{C N}\right)\right]^{2+}(1.936$ and $2.223 \AA)$ due to deprotonation. Complex $\left[\mathbf{C u}\left(\mathbf{C F}_{3} \mathbf{P M P}^{\mathrm{tBu}}-\mathbf{C H O}\right)(\mathbf{C l})\right]$ was prepared from a copper chloride salt $\left(\left[\mathrm{CuCl}_{2}\right] .2 \mathrm{H}_{2} \mathrm{O}\right)$ in the presence of triethylamine. It demonstrates a square pyramidal mononuclear copper complex $(\operatorname{tau}=0.07)$, with the trifluoromethylpyridine coordinated in axial position $(\mathrm{Cu}-\mathrm{N} 2$ bond distance of $2.561 \AA)$ and the phenolate strongly bound in equatorial position ( $\mathrm{Cu}-\mathrm{O} 1$ bond distance of 1.882 $\AA$ ). The equatorial plane is completed by the two N-donors of the ligand, as well as one chloride ligand from the copper source.

[Note: In order to verify the versatility of the nuclearity of the compounds and their interconversion in $\mathrm{CH}_{3} \mathrm{CN}$ we conducted titration experiments (see $\mathrm{ESI}$ ). We titrated a $\mathrm{CH}_{3} \mathrm{CN}$ solution of $\left[\mathrm{Cu}_{2}(\mathrm{HPMP}-\mathbf{C H O})_{2}\right]^{2+}$ by $\mathrm{HClO}_{4}$. At one molar equivalent added (with respect to copper) the spectrum matches that of single crystals of $\left[\mathbf{C u}(\mathbf{H P M P}-\mathbf{C H O})\left(\mathrm{CH}_{3} \mathbf{C N}\right)\right]^{2+}$ dissolved in $\mathrm{CH}_{3} \mathrm{CN}$ (ESI). Conversely, titration of $\left[\mathrm{Cu}(\mathrm{HPMP}-\mathrm{CHO})\left(\mathrm{CH}_{3} \mathbf{C N}\right)\right]^{2+}$ by $\mathrm{NEt}_{3}$ produces, at one molar equivalent added, the spectrum of $\left[\mathrm{Cu}_{2}(\mathbf{H P M P}-\mathbf{C H O})_{2}\right]^{2+}$. Remarkably, titration of $\left[\mathrm{Cu}(\mathrm{MePMP}-\mathrm{CHO})\left(\mathrm{CH}_{3} \mathrm{CN}\right)\right]^{2+}$ by $\mathrm{NEt}_{3}$ produces, at one molar equivalent added, a spectrum distinct from that of $\left[\mathrm{Cu}_{2}(\mathrm{HPMP}-\mathrm{CHO})_{2}\right]^{2+}$, with some features reminiscent of the pyrene derivatives in water at $\mathrm{pH} 6$, demonstrating partial formation of a monomer. EPR monitoring confirms that $\left[\mathrm{Cu}_{2}(\mathrm{HPMP}-\mathrm{CHO})_{2}\right]^{2+}$ is EPR-silent (magnetic coupling between the copper 
centers), and both $\left[\mathrm{Cu}(\mathrm{HPMP}-\mathrm{CHO})\left(\mathrm{CH}_{3} \mathrm{CN}\right)\right]^{2+}$ and $\left[\mathrm{Cu}(\mathrm{MePMP}-\mathrm{CHO})\left(\mathrm{CH}_{3} \mathrm{CN}\right)\right]^{2+}$ are isolated $(\mathrm{S}=1 / 2)$ systems. The spectrum of $\left[\mathbf{C u}(\mathbf{M e P M P}-\mathbf{C H O})\left(\mathbf{C H}_{3} \mathbf{C N}\right)\right]^{2+}$ in the presence of one molar equivalent of $\mathrm{NEt}_{3}$ added shows a loss of ca. $70 \%$ in intensity, which suggests the presence of a mixture of monomer and dimer in solution. We interpret this behaviour by an easier formation of the dimer in the less coordinating acetonitrile (with respect to water) when the ligand features unsubstituted pyridines only. The introduction of a methyl substituent enhances the steric hindrances that further destabilize dimeric structures.]

Hence these combined aqueous solution and solid state data support a dynamic equilibrium, whereby the monomeric phenolate form can be converted into a dimeric form by exogenous ligand release (Scheme 2). This equilibrium shifts towards the monomeric form if the phenolate features a steric bulk in ortho position, or if strongly ligating counter-ion or solvent is used. Conversely, the dimeric form is favored upon concentration (crystallization or surface effect, see below), in less coordinating solvents, and for non-tert-butylated phenolates..$^{28,31}$ 


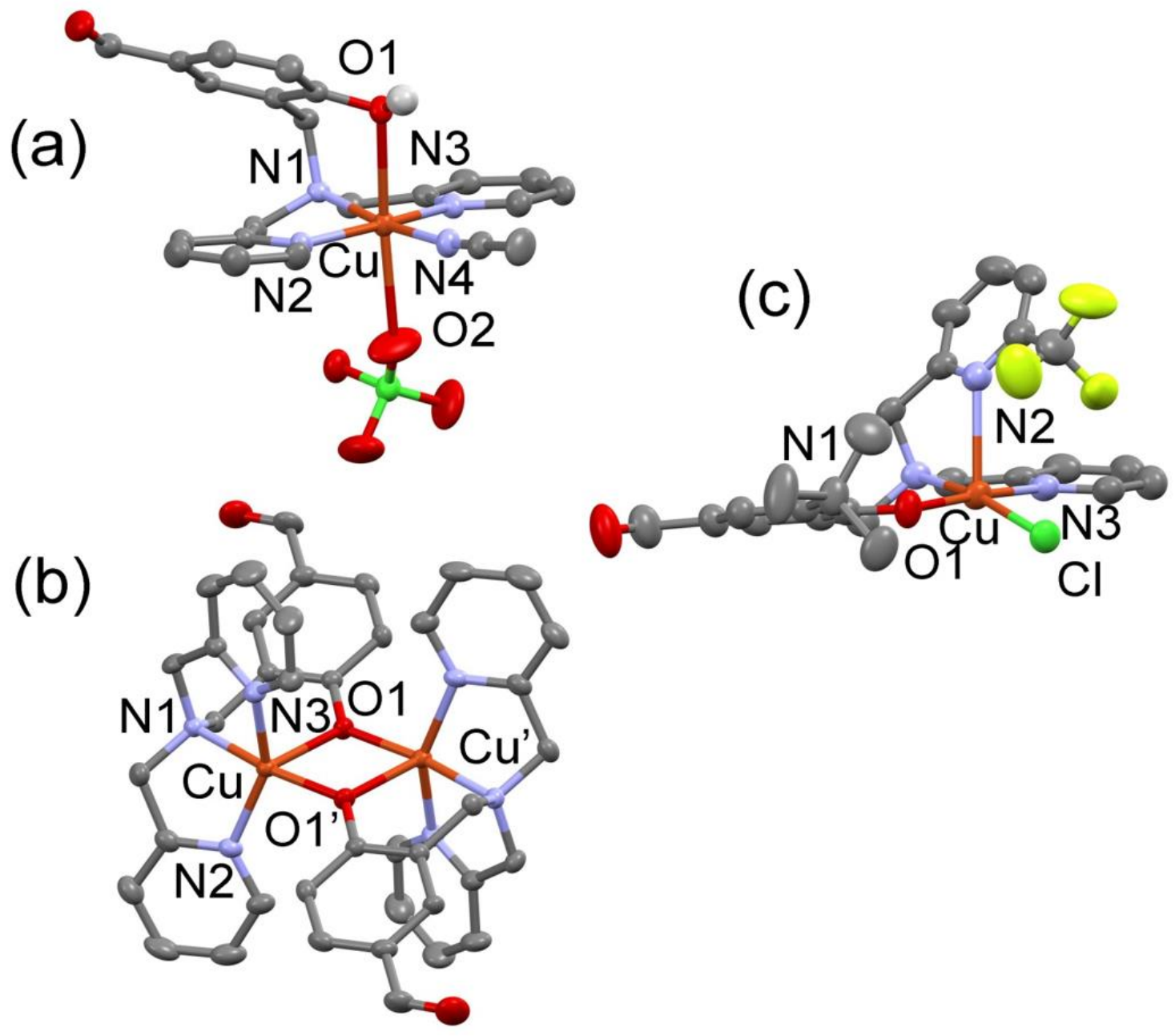

Figure 1. X-ray crystal structures of (a) $[\mathrm{Cu}(\mathrm{HPMP}-\mathrm{CHO})]^{2+}\left(\mathrm{ClO}_{4}\right)^{-}$and (b) $\left[\mathrm{Cu}_{2}(\mathrm{HPMP}-\right.$ $\left.\mathbf{C H O})_{2}\right]^{2+}$ and (c) $\left[\mathbf{C u}\left(\mathbf{C F}_{3} \mathbf{P M P}^{\text {tBu}}-\mathbf{C H O}\right)(\mathbf{C l})\right]$. The hydrogen atoms (except the phenolic ones) are omitted for clarity.

Multi-walled CNTs (MWCNTs)-coated glassy-carbon (GC) electrodes were then modified with the pyrene-appended complexes by in situ formation of the complex in a $\mathrm{DMF} / \mathrm{H}_{2} \mathrm{O}$ mixture $(1: 1$ $\mathrm{v} / \mathrm{v})$ through addition of two equivalents of $\left[\mathrm{Cu}\left(\mathrm{ClO}_{4}\right)_{2}\right] .6 \mathrm{H}_{2} \mathrm{O}$ to a solution of the corresponding PMP-pyrene derivative. Next, MWCNT electrodes were soaked in this solution for $45 \mathrm{~min}$. The 
electrochemical behavior of the modified MWCNT electrodes were then investigated by cyclic voltammetry (CV) under argon between $\mathrm{pH} 3$ and $\mathrm{pH} 9$ using a $0.1 \mathrm{M}$ Britton-Robinson buffer solution (Fig. 2).
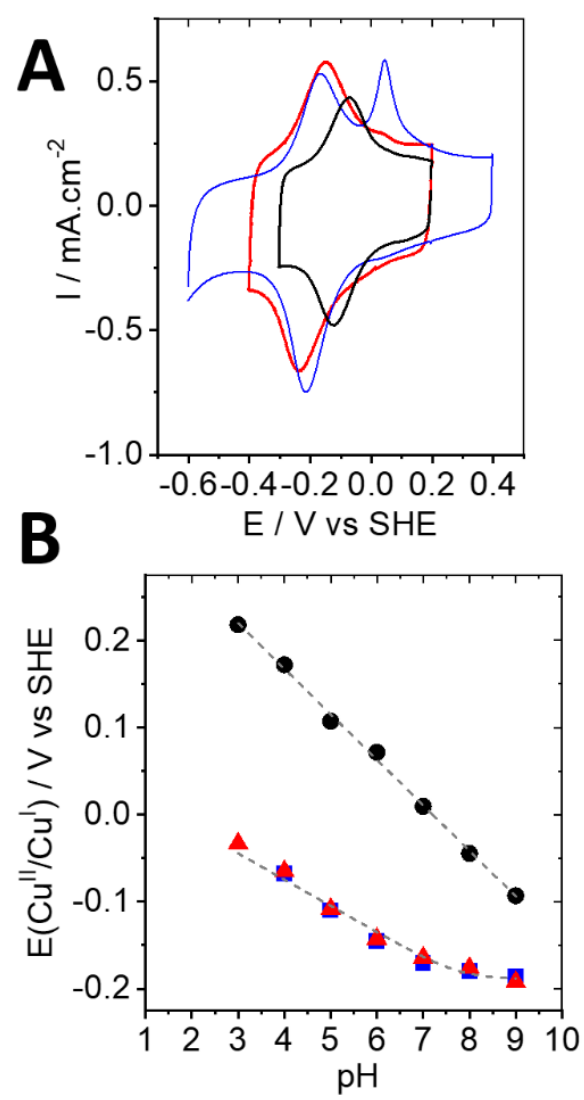

Figure 2. (A) $\mathrm{CVs}$ of $\left[\mathrm{Cu}\left(\mathrm{CF}_{3} \mathrm{PMP}^{\mathrm{tBu}}\right.\right.$-pyrene] (black), [Cu(MePMP-pyrene)] (red) and [Cu(HPMP-pyrene)] (blue), (straight line) immobilized on the MWCNT electrode collected at pH 9 (0.1 M Britton Robinson buffer) under argon $\left(v=10 \mathrm{mV} \mathrm{s}^{-1}\right)$; (B) Corresponding experimental and fitted (gray dashed line) evolution of the redox potential of the $\mathrm{Cu}^{\mathrm{II}} / \mathrm{Cu}^{\mathrm{I}}$ redox couple for as a function of the $\mathrm{pH}$ for of $\left[\mathrm{Cu}\left(\mathrm{CF}_{3} \mathbf{P M P}^{\mathrm{tBu}}\right.\right.$-pyrene] $(\bullet)$, [Cu(MePMP-pyrene)] (A) and [Cu(HPMP-pyrene)] (घ), The geometrical surface of the electrode $\left(0.07 \mathrm{~cm}^{-2}\right)$ was used to calculate current densities. 
A quasi-reversible redox system is observed at $\mathrm{E}_{1 / 2}=-0.09 \mathrm{~V}$ vs $\mathrm{SHE}$ at $\mathrm{pH} 9$ for $\left[\mathbf{C u}\left(\mathbf{C F}_{3} \mathbf{P M P}^{\text {tBu}}\right.\right.$-pyrene] and $\mathrm{E}_{1 / 2}=-0.19 \mathrm{~V}$ vs. SHE for both [Cu(MePMP-pyrene)] and [Cu(HPMP-pyrene)]. This redox system is assigned to the $\mathrm{Cu}^{\mathrm{II}} / \mathrm{Cu}^{\mathrm{I}}$ redox couple. As expected, a shift of $100 \mathrm{mV}$ towards more positive potential is observed for $\left[\mathbf{C u}\left(\mathbf{C F}_{3} \mathbf{P M P}^{\mathrm{tBu}}\right.\right.$-pyrene]. A second oxidation system at more positive potentials is observed for all complexes when decreasing the pHs (figure S19). This system becomes prevalent at low $\mathrm{pH}$ for the $\left[\mathbf{C u}\left(\mathbf{C F}_{3} \mathbf{P M P} \mathbf{P}^{\mathrm{tBu}}\right.\right.$-pyrene]. Furthermore, this system is also increased at lower scan rates. This EC-type mechanism has already been observed for the previously-described [Cu(MePMP ${ }^{\text {tBu}}$-pyrene] and might correspond to the electrochemically-induced protonation of the phenolate into phenol. ${ }^{17,18}$.

The $\mathrm{pH}$ dependence was monitored for the three complexes (Fig. 2B). [Cu(CFiPMP ${ }^{\text {tBu}}$-pyrene] exhibits a typical linear behavior with a slope of $53 \mathrm{mV}$ per $\mathrm{pH}$ unit, which corresponds to a $1 \mathrm{H}^{+} / 1 \mathrm{e}^{-}$ redox couple, very similar to the $\left[\mathbf{C u}\left(\mathbf{M e P M P}{ }^{\text {tBu}}\right.\right.$-pyrene] derivative. On the contrary, both [Cu(MePMP-pyrene)] and [Cu(HPMP-pyrene)] exhibit a pH dependence which was confidently modeled by eq. (1):

$$
E_{1 / 2}=E_{1 / 2}\left(C u_{\text {basic }}^{I I / I}\right)+\frac{2.3 R T}{n F} * \log \left(1+\frac{\left[H^{+}\right]}{\left[K_{a} \text { red }\right]}\right) \text { (1) }
$$

Where $\mathrm{R}$ is the gas constant, $\mathrm{T}$ the temperature, $\mathrm{F}$ the Faraday constant and $\mathrm{n}$ the number of electrons involved in the redox system. $\mathrm{K}_{\mathrm{a}}{ }^{\text {red }}$ is the proton dissociation constant for the reduced form and $\mathrm{E}_{1 / 2}\left(\mathrm{Cu}^{\mathrm{I} / /}\right)$ is the limiting value of $\mathrm{E}_{1 / 2}$ at $\mathrm{pH}$ above $\mathrm{pK}_{\mathrm{a}}{ }^{\text {red }}$. This fit is well-modeled using $\mathrm{n}=2$. This corresponds to a slope of $30 \mathrm{mV}$ between $\mathrm{pH}=3$ and $\mathrm{pH}=9$ and strongly supports the presence of a dinuclear $\mathrm{Cu}(\mathrm{II})$ species immobilized at the electrode surface, which structure may be reminiscent of the dimers crystallized from the aldehyde precursors (see above). This $\mathrm{pH}$ dependence also indicates the presence of an acid-base couple for the reduced $\mathrm{Cu}(\mathrm{I})-\mathrm{Cu}(\mathrm{I})$ species with a $\mathrm{pK}_{\mathrm{a}}^{\text {red }}$ of $7.8 \pm 0.3\left(\mathrm{R}^{2}=0.98\right)$, corresponding to the deprotonated $\mathrm{Cu}(\mathrm{I})-\mathrm{Cu}(\mathrm{I})$ species at 
high $\mathrm{pH}$. The electrochemical behavior of [Cu(MePMP-pyrene)] and [Cu(HPMP-pyrene)] are very similar, indicating that the presence of the methyl group has negligible influence on the electronic environment of $\mathrm{Cu}(\mathrm{II})$ for the complexes in water. Scheme 3 summarizes the proposed structures of the redox couple involved in the $\mathrm{pH}$ dependent evolution of the $\mathrm{Cu}^{\mathrm{II}} / \mathrm{Cu}^{\mathrm{I}}$ redox potential.

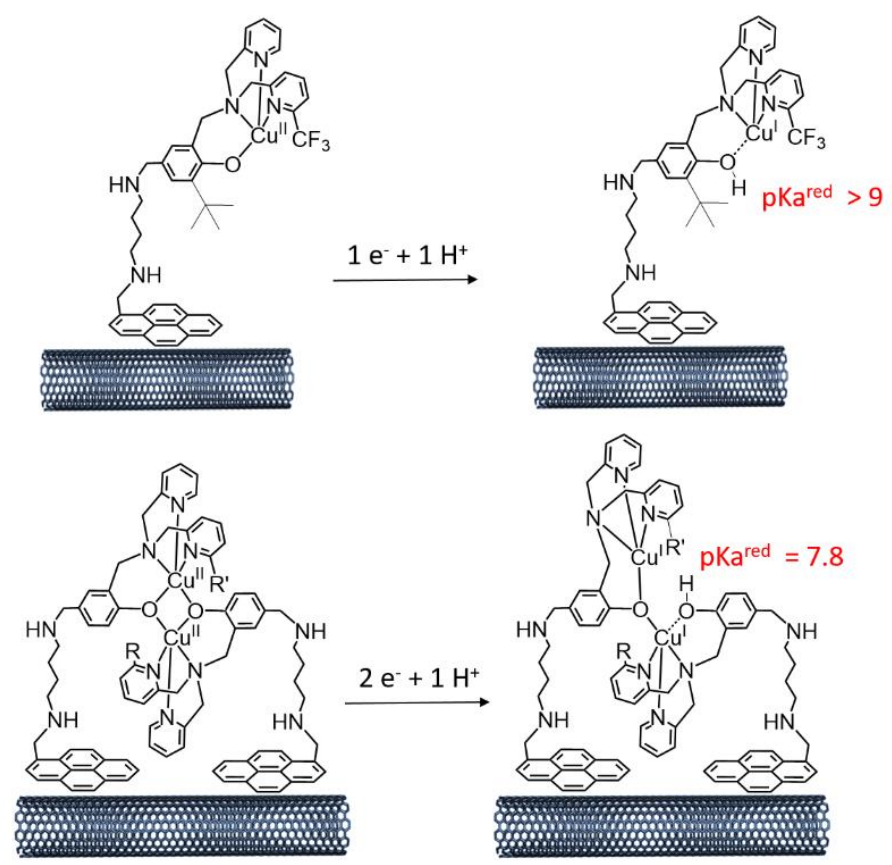

Scheme 3. Schematic representation of the proposed immobilized complex redox couple. The amines of the putrescine linker might be protonated depending on the $\mathrm{pH}$

From the integration of the charge under the reduction peak and taking into account the monomer form for all complexes, a surface coverage of $0.42,0.70$ and $0.96 \mathrm{nmol} \mathrm{cm}^{-2}$ were measured for [Cu(CF3 PMP ${ }^{\text {tBu}}$-pyrene)], [Cu(HPMP-pyrene)], [Cu(MePMP-pyrene)] and [Cu(HPMPpyrene)] respectively. Furthermore, studies at different scan rates indicate a linear dependence of both anodic and cathodic peak currents in respect to scan rates. In addition, the fact that the CVs 
are stable over multiple scanning confirms the stable immobilization of the series of complexes on MWCNTs.

The immobilization of these complexes was further confirmed by X-Ray Photoelectron Spectroscopy (XPS). XPS were performed for [Cu(CF3 PMP ${ }^{\text {tBu }}$-pyrene)] and [Cu(MePMP-

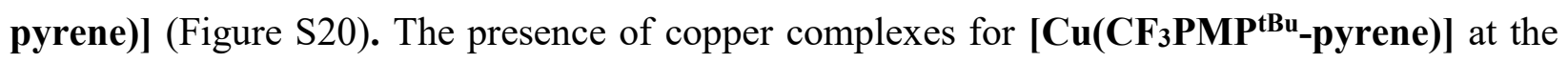
surface of MWCNTs is indicated by the peaks at 933 and $952.7 \mathrm{eV}$, corresponding to the $\mathrm{Cu} 2 \mathrm{p} 1 / 2$ and $2 \mathrm{p} 3 / 2$ binding energy, respectively. This value, as well as the absence of satellite peaks suggested that $\mathrm{Cu}(\mathrm{II})$ is fully reduced into $\mathrm{Cu}(\mathrm{I})$ under the X-ray beam. ${ }^{19,33}$ In the case of [Cu(MePMP-pyrene)], in addition to the peak corresponding to $\mathrm{Cu}(\mathrm{I})$, two peaks are observed at 934.8 and $954.2 \mathrm{eV}$ for $\mathrm{Cu} 2 \mathrm{p} 1 / 2$ and 2p3/2 respectively, accompanied with a satellite peak at 944 $\mathrm{eV}$. This is indicative of the presence of both $\mathrm{Cu}(\mathrm{II})$ and $\mathrm{Cu}(\mathrm{I})$ at the surface of MWCNTs. This suggests that a partial reduction $(50 \%)$ of $\mathrm{Cu}(\mathrm{II})$ into $\mathrm{Cu}(\mathrm{I})$ occurs for [Cu(MePMP-pyrene)] as compared to $\left[\mathbf{C u}\left(\mathbf{C F}_{3} \mathbf{P M P}^{\mathrm{BBu}}\right.\right.$-pyrene)]. This might be expected since [Cu(CF $\mathbf{C F}_{3} \mathbf{P M P}^{\mathrm{tBu}}$-pyrene)] is easier to reduce according to redox potentials measured by electrochemistry. Integration of the $\mathrm{N}$ 1s energy level observed at $400 \mathrm{eV}$ gives an estimation of the ratio $\mathrm{N} / \mathrm{Cu}$ of 5.6 and 5.0 for [Cu(MePMP-pyrene) $]$ and $\left[\mathbf{C u}\left(\mathbf{C F}_{3}\right.\right.$ PMP $^{\text {tBu }}$-pyrene $\left.)\right]$ respectively, close to the expected theoretical value of 5 .

The ORR activity of the modified hybrid MWCNT electrodes was next investigated by CV and Rotating-Ring-Disk Electrode (RDDE) experiments in the presence of $\mathrm{O}_{2}$. Figure 3 displays $\mathrm{CV}$ performed in the presence of $\mathrm{O}_{2}$ for all modified MWCNT electrodes and a nonmodified MWCNT electrode. 


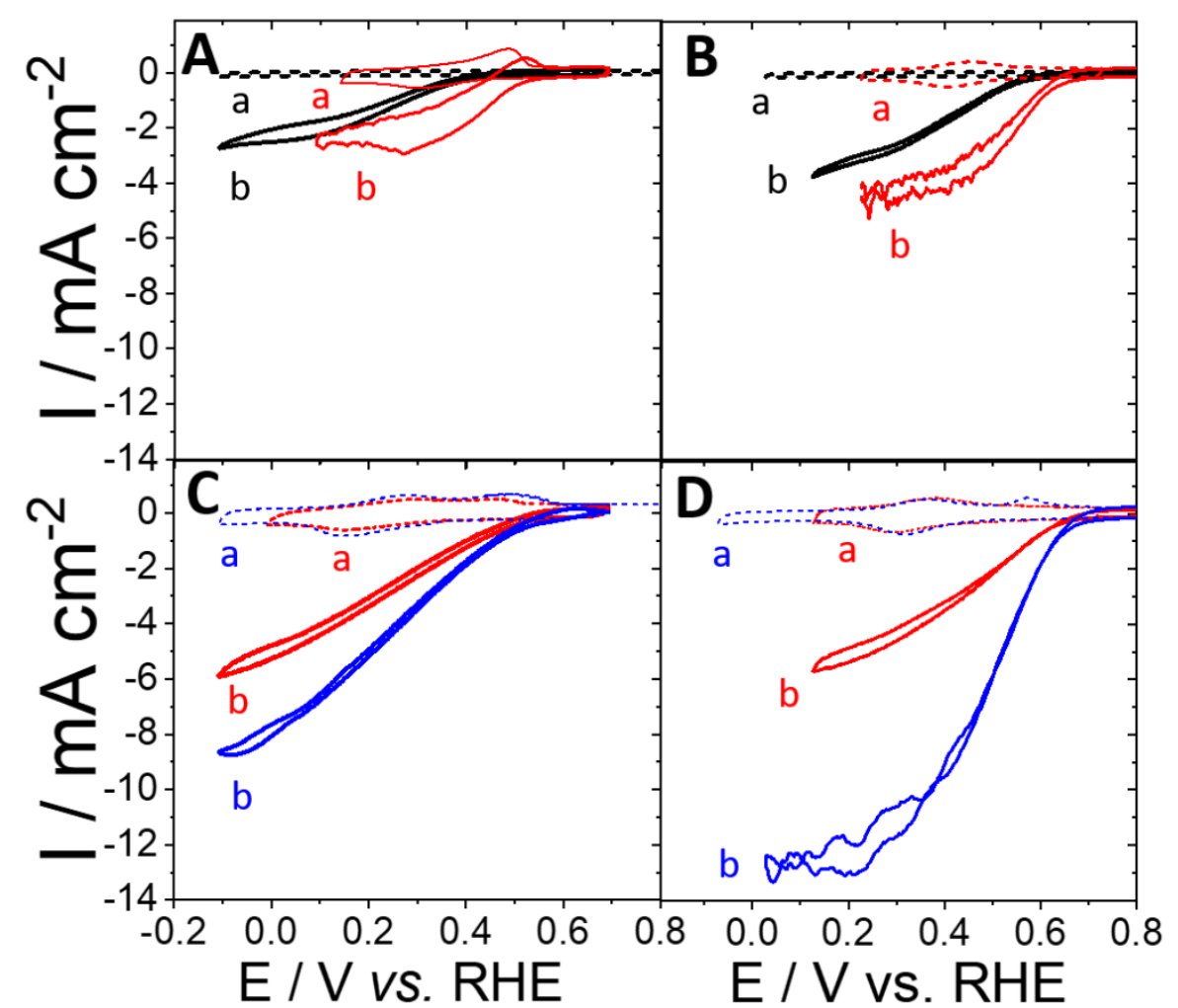

Figure 3. (A) CVs of pristine MWCNT (black) and $\left[\mathbf{C u}\left(\mathbf{C F}_{3} \mathbf{P M P}^{\text {tBu}}\right.\right.$-pyrene] /MWCNT (red) electrode under (a, dashed line) $\mathrm{Ar}$ and ( $\mathrm{b}$, straight line) $\mathrm{O}_{2}$ (0.1 M Britton Robinson buffer, $\mathrm{pH}$ 4, $v=10 \mathrm{mV} \mathrm{s}^{-1}$ ) (B) at pH 9; (C) CVs of [Cu(MePMP-pyrene)]/MWCNT (red) and [Cu(HPMPpyrene)]/MWCNT (blue) electrode under (a, dashed line) $\mathrm{Ar}$ and (b, straight line) $\mathrm{O}_{2}(0.1 \mathrm{M}$ Britton Robinson buffer, $\mathrm{pH} 4, v=10 \mathrm{mV} \mathrm{s}^{-1}$ ) and (D) $\mathrm{pH} 9$

All complexes exhibit ORR electroactivity between $\mathrm{pH} 4$ and $\mathrm{pH} 9$ (Fig.3A and B). The onset potential measured by Tafel plot analysis decreases linearly with increasing $\mathrm{pH}$, with a similar slope of around $30 \mathrm{mV}$ per $\mathrm{pH}$ unit for all complexes (Fig. S21A and B). This is consistent with a $2 \mathrm{e}^{-} / 1 \mathrm{H}^{+}$limiting step that might involve a stable, coordinated, hydroperoxo species. ${ }^{13,17,18,34}$. Onset potentials of $0.70,0.74$ and $0.78 \mathrm{~V}$ vs. RHE and maximum current densities of 4.3, 5.4 and 12.7 $\mathrm{mA} \mathrm{cm}{ }^{-2}$ were measured for $\left[\mathrm{Cu}\left(\mathrm{CF}_{3} \mathbf{P M P}^{\mathrm{tBu}}\right.\right.$-pyrene)], [Cu(MePMP-pyrene)] and [Cu(HPMP- 
pyrene)], respectively. According to respective surface coverages, maximum turnover frequencies (TOF) of 36, 21 and $26 \mathrm{~s}^{-1}$ could be determined for [Cu(HPMP-pyrene)], [Cu(MePMP-pyrene)] and [Cu(CF3 PMP $^{\text {tBu }}$-pyrene)]/ MWCNT electrode respectively. The amount of $\mathrm{H}_{2} \mathrm{O}_{2}$ and the number of electrons involved in ORR were quantified by RDDE (Figure S21C). Low amounts of $\mathrm{H}_{2} \mathrm{O}_{2}$ of 6,22 and $15 \%$ were measured for [Cu(CF $\mathbf{C F}_{3} \mathbf{P M P}{ }^{\mathrm{tBu}}$-pyrene)], [Cu(MePMP-pyrene)] and [Cu(HPMP-pyrene)] respectively. According to RRDE experiments, all complexes exhibit a 3.6-3.8 electron mechanism towards ORR. The ORR performances of this family of complexes are summarized in table 1 .

Table 1. ORR Electrochemical characteristics of the hybrid nanostructured electrodes

\begin{tabular}{|l|l|l|l|l|}
\hline & $\Gamma_{\text {Max }}\left(\mathrm{nmol} \mathrm{cm}^{-2}\right)$ & TOF $\left(\mathrm{s}^{-1}\right)$ & $\% \mathrm{H}_{2} \mathrm{O}_{2}$ & $\mathrm{n}_{\text {electrons }}$ \\
\hline Cu(CF3 PMP $^{\text {tBu-pyrene) }]}$ & $0.42(+/-0.05)$ & $26(+/-8)$ & $6(+/ 3)$ & $3.8(+/-2)$ \\
\hline [Cu(MePMP-pyrene)] & $0.70(+/-0.05)$ & $20(+/-5)$ & $22(+/-4)$ & $3.6(+/-1)$ \\
\hline Cu(HPMP-pyrene)] & $0.92(+/-0.05)$ & $36(+/-5)$ & $15(+/-5)$ & $3.7(+/-1)$ \\
\hline
\end{tabular}

[Cu(HPMP-pyrene)] displays the highest catalytic performances towards ORR between $\mathrm{pH} 4$ and $\mathrm{pH}$ 9. These results shows that the less-protected mononuclear copper complex is highly efficient towards ORR. The fact that $\left[\mathbf{C u}\left(\mathbf{C F}_{3} \mathbf{P M P}{ }^{\mathbf{t B u}}\right.\right.$-pyrene $\left.)\right]$ exhibits similar overpotentials and low $\mathrm{H}_{2} \mathrm{O}_{2}$ production suggests that the catalytic species also involves a $\mathrm{Cu}_{2}-\mathrm{O}_{2}$ adduct, as it was hypothesized for different types of surface-confined mononuclear copper complexes. ${ }^{16-18,25}$ It is noteworthy that the shift of redox potential observed under $\operatorname{Ar}$ for $\left[\mathbf{C u}_{(\mathbf{C F}} \mathbf{P} \mathbf{P M P}^{\mathrm{tBu}}\right.$-pyrene)] is not translated for the catalytic species under $\mathrm{O}_{2}$. This absence of effect of the redox potential of the $\mathrm{Cu}^{\mathrm{II}} / \mathrm{Cu}^{\mathrm{I}}$ couple on the ORR overpotential is also observed for the tris(2-pyridylmethyl)amine copper complex adsorbed on carbon black. ${ }^{35}$ In the case of [Cu(MePMP-pyrene)] and 
[Cu(HPMP-pyrene)] we observed twice-higher catalyst loadings as compared to [Cu(CF C PMP $^{\text {tBu }}$-pyrene $\left.)\right]$, which might suggest that dimerization favor the immobilization of the copper complexes on MWCNT sidewalls. This allows for current densities as high as $12.7 \mathrm{~mA} \mathrm{~cm}^{-}$ ${ }^{2}$ for [Cu(HPMP-pyrene)]. In the light of the results obtained for the dinuclear copper complex based on a HBPMP-type ligand ${ }^{19}$ (Scheme 4 ) which shares structural similarity with the dimers herein proposed, we propose a dinuclear catalytic species on MWCNT despite mononuclear structure in aqueous solution (scheme 4).
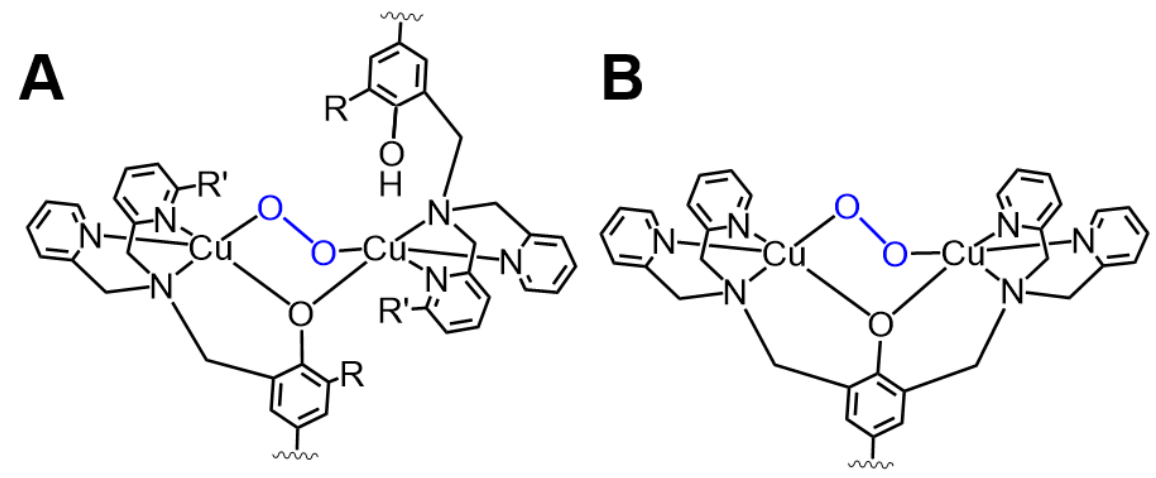

Scheme 4. Structures of the possible catalytic $\mathrm{O}_{2}$-adduct for (A) the copper complexes derived from PMP-pyrene and for (B) the dinuclear copper complex derived from HBPMP-pyrene ligand $^{19}$

Dimerization of the complexes favors the activation of $\mathrm{O}_{2}$ upon reduction, which is concomitant with the decoordination-protonation of one phenolate group. Best performances were obtained for the derivative bearing no bulky groups, which confirms that unprotected ligands favor early surface-confined dimerization of the complex and favorable subsequent oxygen binding. Furthermore, the increased onset potential and increased TOF $\left(72 \mathrm{~s}^{-1}\right.$ if the dimer is taken as the 
catalytic species) for [Cu(HPMP-pyrene)], as compared to the dinuclear copper complex with HBPMP ligand $\left(E_{\text {onset }}=0.71 \mathrm{~V}\right.$, TOF $\left.=39 \mathrm{~s}^{-1}\right),{ }^{19}$ might arise from the presence of a second phenol group which act as a proton relay in the ORR mechanism. For comparison, in terms of ORR overpotential, it is still below several copper-complex-based based on a polyvinylimidazole or tris(pyridin-2-ylethyl)amine ligands, reaching respective onset values of $1.05 \mathrm{~V}(\mathrm{pH} 13)^{36}$ and 0.81 $\mathrm{V}(\mathrm{pH} 10)^{35}$. Other dinuclear $\mathrm{Cu}$ complexes with tris(pyridin-2-ylmethyl)amine, ${ }^{25}$ substituted phenanthrolines ${ }^{16,37}$, hexaazamacrocycles or ${ }^{38}$ aminotriazoles $^{26}$, exhibit onset potentials between $0.65-0.73 \mathrm{~V}$ vs RHE at neutral $\mathrm{pH}$. This demonstrates that further improvements are still possible in this series.

In conclusion we describe a new family of unprotected phenolato-copper complexes bearing pyrene groups. Their successful immobilization on MWCNT electrodes induces their dimerization on surface. As compared to mononuclear complexes with bulkier groups or dinuclear complex with structural similarities, electrochemical studies demonstrate the enhancement of ORR activity of this family of complexes, owing to this early dimerization process. These hybrid nanostructured electrodes exhibit high efficiency towards ORR. Future studies will be aimed at tuning the electronic environment of copper centers as well as tuning the nature of proton relays in order to decrease the overpotential of this family of complex towards ORR.

Supporting Information. Experimental details, Table S1-S2, and Figure S1 to S21

\section{Corresponding Author}

Alan.le-goff@univ-grenoble-alpes.fr , fabrice.thomas@univ-grenoble-alpes.fr

\section{Author Contributions}


The manuscript was written with contributions of all authors. All authors have given approval to the final version of the manuscript.

\section{Acknowledgments}

This work was supported by the Ministère de l'Environnement, de l'Energie et de la Mer and the Agence Nationale de la Recherche through the LabEx ARCANE programe (ANR-11-LABX0003-01) and the Graduate School on Chemistry, Biology and Health of Univ Grenoble Alpes CBH-EUR-GS (ANR-17-EURE-0003). The authors acknowledge support from the plateforme de Chimie NanoBio ICMG FR 2607 (PCN-ICMG).

\section{REFERENCES}

(1) Shao, M.; Chang, Q.; Dodelet, J.-P.; Chenitz, R. Recent Advances in Electrocatalysts for Oxygen Reduction Reaction. Chem. Rev. 2016, 116 (6), 3594-3657. https://doi.org/10.1021/acs.chemrev.5b00462.

(2) Jaouen, F.; Proietti, E.; Lefèvre, M.; Chenitz, R.; Dodelet, J.-P.; Wu, G.; Chung, H. T.; Johnston, C. M.; Zelenay, P. Recent Advances in Non-Precious Metal Catalysis for OxygenReduction Reaction in Polymer Electrolyte Fuel Cells. Energy Environ. Sci. 2010, 4 (1), 114-130. https://doi.org/10.1039/C0EE00011F.

(3) Lewis, E. A.; Tolman, W. B. Reactivity of Dioxygen-Copper Systems. Chem. Rev. 2004, 104 (2), 1047-1076. https://doi.org/10.1021/cr020633r.

(4) Solomon, E. I.; Heppner, D. E.; Johnston, E. M.; Ginsbach, J. W.; Cirera, J.; Qayyum, M.; Kieber-Emmons, M. T.; Kjaergaard, C. H.; Hadt, R. G.; Tian, L. Copper Active Sites in Biology. Chem. Rev. 2014, 114 (7), 3659-3853. https://doi.org/10.1021/cr400327t.

(5) Whittaker, J. W. Free Radical Catalysis by Galactose Oxidase. Chem. Rev. 2003, 103 (6), 2347-2364. https://doi.org/10.1021/cr020425z.

(6) Soukharev, V.; Mano, N.; Heller, A. A Four-Electron O2-Electroreduction Biocatalyst Superior to Platinum and a Biofuel Cell Operating at 0.88 V. J. Am. Chem. Soc. 2004, 126 (27), 8368-8369. https://doi.org/10.1021/ja0475510.

(7) Blanford, C. F.; Heath, R. S.; Armstrong, F. A. A Stable Electrode for High-Potential, Electrocatalytic O2 Reduction Based on Rational Attachment of a Blue Copper Oxidase to a Graphite Surface. Chem. Commun. 2007, 1710-1712. https://doi.org/10.1039/B703114A.

(8) Le Goff, A.; Holzinger, M.; Cosnier, S. Recent Progress in Oxygen-Reducing Laccase Biocathodes for Enzymatic Biofuel Cells. Cell. Mol. Life Sci. 2015, 72 (5), 941-952. https://doi.org/10.1007/s00018-014-1828-4.

(9) Bullock, R. M.; Chen, J. G.; Gagliardi, L.; Chirik, P. J.; Farha, O. K.; Hendon, C. H.; Jones, C. W.; Keith, J. A.; Klosin, J.; Minteer, S. D.; Morris, R. H.; Radosevich, A. T.; Rauchfuss, 
T. B.; Strotman, N. A.; Vojvodic, A.; Ward, T. R.; Yang, J. Y.; Surendranath, Y. Using Nature's Blueprint to Expand Catalysis with Earth-Abundant Metals. Science 2020, 369 (6505). https://doi.org/10.1126/science.abc3183.

(10) Fukuzumi, S.; Lee, Y.-M.; Nam, W. Mechanisms of Two-Electron versus Four-Electron Reduction of Dioxygen Catalyzed by Earth-Abundant Metal Complexes. ChemCatChem 2018, 10 (1), 9-28. https://doi.org/10.1002/cctc.201701064.

(11) Zhao, Y.-M.; Yu, G.-Q.; Wang, F.-F.; Wei, P.-J.; Liu, J.-G. Bioinspired Transition-Metal Complexes as Electrocatalysts for the Oxygen Reduction Reaction. Chemistry - A European Journal 2019, 25 (15), 3726-3739. https://doi.org/10.1002/chem.201803764.

(12) Bullock, R. M.; Das, A. K.; Appel, A. M. Surface Immobilization of Molecular Electrocatalysts for Energy Conversion. Chemistry - A European Journal 2017, 23 (32), 7626-7641. https://doi.org/10.1002/chem.201605066.

(13) Thorseth, M. A.; Tornow, C. E.; Tse, E. C. M.; Gewirth, A. A. Cu Complexes That Catalyze the Oxygen Reduction Reaction. Coordination Chemistry Reviews 2013, 257 (1), 130-139. https://doi.org/10.1016/j.ccr.2012.03.033.

(14) Das, D.; Lee, Y.-M.; Ohkubo, K.; Nam, W.; Karlin, K. D.; Fukuzumi, S. TemperatureIndependent Catalytic Two-Electron Reduction of Dioxygen by Ferrocenes with a Copper(II) Tris[2-(2-Pyridyl)Ethyl]Amine Catalyst in the Presence of Perchloric Acid. $J$. Am. Chem. Soc. 2013, 135 (7), 2825-2834. https://doi.org/10.1021/ja312523u.

(15) Kakuda, S.; Peterson, R. L.; Ohkubo, K.; Karlin, K. D.; Fukuzumi, S. Enhanced Catalytic Four-Electron Dioxygen (O2) and Two-Electron Hydrogen Peroxide (H2O2) Reduction with a Copper(II) Complex Possessing a Pendant Ligand Pivalamido Group. J. Am. Chem. Soc. 2013, 135 (17), 6513-6522. https://doi.org/10.1021/ja3125977.

(16) McCrory, C. C. L.; Devadoss, A.; Ottenwaelder, X.; Lowe, R. D.; Stack, T. D. P.; Chidsey, C. E. D. Electrocatalytic O2 Reduction by Covalently Immobilized Mononuclear Copper(I) Complexes: Evidence for a Binuclear Cu2O2 Intermediate. J. Am. Chem. Soc. 2011, 133 (11), 3696-3699. https://doi.org/10.1021/ja106338h.

(17) Tse, E. C. M.; Schilter, D.; Gray, D. L.; Rauchfuss, T. B.; Gewirth, A. A. Multicopper Models for the Laccase Active Site: Effect of Nuclearity on Electrocatalytic Oxygen Reduction. Inorg. Chem. 2014, 53 (16), 8505-8516. https://doi.org/10.1021/ic501080c.

(18) Gentil, S.; Serre, D.; Philouze, C.; Holzinger, M.; Thomas, F.; Le Goff, A. Electrocatalytic $\mathrm{O} 2$ Reduction at a Bio-Inspired Mononuclear Copper Phenolato Complex Immobilized on a Carbon Nanotube Electrode. Angew. Chem. Int. Ed. 2016, 55 (7), 2517-2520. https://doi.org/10.1002/anie.201509593.

(19) Gentil, S.; Molloy, J. K.; Carrière, M.; Hobballah, A.; Dutta, A.; Cosnier, S.; Shaw, W. J.; Gellon, G.; Belle, C.; Artero, V.; Thomas, F.; Le Goff, A. A Nanotube-Supported Dicopper Complex Enhances Pt-Free Molecular H2/Air Fuel Cells. Joule 2019, 3 (8), 2020-2029. https://doi.org/10.1016/j.joule.2019.07.001.

(20) Gentil, S.; Lalaoui, N.; Dutta, A.; Nedellec, Y.; Cosnier, S.; Shaw, W. J.; Artero, V.; Le Goff, A. Carbon-Nanotube-Supported Bio-Inspired Nickel Catalyst and Its Integration in Hybrid Hydrogen/Air Fuel Cells. Angew. Chem. Int. Ed. 2017, 56 (7), 1845-1849. https://doi.org/10.1002/anie.201611532.

(21) Elouarzaki, K.; Le Goff, A.; Holzinger, M.; Thery, J.; Cosnier, S. Electrocatalytic Oxidation of Glucose by Rhodium Porphyrin-Functionalized MWCNT Electrodes: Application to a Fully Molecular Catalyst-Based Glucose/O2 Fuel Cell. J. Am. Chem. Soc. 2012, 1407814085 . 
(22) Artero, V. Bioinspired Catalytic Materials for Energy-Relevant Conversions. Nat. Energy 2017, 2 (9), 17131. https://doi.org/10.1038/nenergy.2017.131.

(23) Coutard, N.; Kaeffer, N.; Artero, V. Molecular Engineered Nanomaterials for Catalytic Hydrogen Evolution and Oxidation. Chem. Commun. 2016, 52 (95), 13728-13748. https://doi.org/10.1039/c6cc06311j.

(24) Brushett, F. R.; Thorum, M. S.; Lioutas, N. S.; Naughton, M. S.; Tornow, C.; Jhong, H.-R. "Molly"; Gewirth, A. A.; Kenis, P. J. A. A Carbon-Supported Copper Complex of 3,5Diamino-1,2,4-Triazole as a Cathode Catalyst for Alkaline Fuel Cell Applications. 2010, 12185-12187.

(25) Thorseth, M. A.; Letko, C. S.; Rauchfuss, T. B.; Gewirth, A. A. Dioxygen and Hydrogen Peroxide Reduction with Hemocyanin Model Complexes. Inorg. Chem. 2011, 50 (13), 6158-6162. https://doi.org/10.1021/ic200386d.

(26) Thorum, M. S.; Yadav, J.; Gewirth, A. A. Oxygen Reduction Activity of a Copper Complex of 3,5-Diamino-1,2,4-Triazole Supported on Carbon Black. Angew. Chem. Int. Ed. 2009, 48 (1), 165-167. https://doi.org/10.1002/anie.200803554.

(27) McCrory, C. C. L.; Ottenwaelder, X.; Stack, T. D. P.; Chidsey, C. E. D. Kinetic and Mechanistic Studies of the Electrocatalytic Reduction of $\mathrm{O} 2$ to $\mathrm{H} 2 \mathrm{O}$ with Mononuclear $\mathrm{Cu}$ Complexes of Substituted 1,10-Phenanthrolines. J. Phys. Chem. A 2007, 111 (49), 1264112650. https://doi.org/10.1021/jp076106z.

(28) Berthet, N.; Martel-Frachet, V.; Michel, F.; Philouze, C.; Hamman, S.; Ronot, X.; Thomas, F. Nuclease and Anti-Proliferative Activities of Copper(II) Complexes of N3O Tripodal Ligands Involving a Sterically Hindered Phenolate. Dalton Trans. 2013, 42 (23), 84688483. https://doi.org/10.1039/C3DT32659D.

(29) In order to prevent precipitation in the investigated $\mathrm{pH}$ range it was necessary to add $30 \%$ (vol) of DMF. .

(30) The Spin Hamiltonian Parameters Obtained from Simulation Are: At PH 6.89: G// = 2.265 and $\mathrm{G}_{-} \mathrm{L}_{-}=2.059$, with $\mathrm{A} / /=505 \mathrm{MHz}$ and $\mathrm{A} \_\mathrm{L}=30 \mathrm{MHz}$; PH 2.5: G// $=2.264$ and $\mathrm{G}_{-} \mathrm{L}_{-}$ $=2.05 \overline{7}$, with $\mathrm{A} / /=537 \mathrm{MHz}$ and $\mathrm{A}_{-} \mathrm{L}_{-}=10 \mathrm{M} \mathrm{Hz}$.

(31) Michel, F.; Thomas, F.; Hamman, S.; Saint-Aman, E.; Bucher, C.; Pierre, J.-L. Galactose Oxidase Models: Solution Chemistry, and Phenoxyl Radical Generation Mediated by the Copper Status. Chemistry - A European Journal 2004, 10 (17), 4115-4125. https://doi.org/10.1002/chem.200400099.

(32) W. Addison, A.; Nageswara Rao, T.; Reedijk, J.; Rijn, J. van; C. Verschoor, G. Synthesis, Structure, and Spectroscopic Properties of Copper( II ) Compounds Containing NitrogenSulphur Donor Ligands; the Crystal and Molecular Structure of Aqua[1,7-Bis( N Methylbenzimidazol-2'-Y1)-2,6-Dithiaheptane]Copper( II ) Perchlorate. Journal of the Chemical Society, Dalton Transactions 1984, 0 (7), 1349-1356. https://doi.org/10.1039/DT9840001349.

(33) Losev, A.; Rostov, K.; Tyuliev, G. Electron Beam Induced Reduction of CuO in the Presence of a Surface Carbonaceous Layer: An XPS/HREELS Study. Surface Science 1989, 213 (2), 564-579. https://doi.org/10.1016/0039-6028(89)90313-0.

(34) Orio, M.; Jarjayes, O.; Kanso, H.; Philouze, C.; Neese, F.; Thomas, F. X-Ray Structures of Copper(II) and Nickel(II) Radical Salen Complexes: The Preference of Galactose Oxidase for Copper(II). Angewandte Chemie International Edition 2010, 49 (29), 4989-4992. https://doi.org/10.1002/anie.201001040. 
(35) Thorseth, M. A.; Letko, C. S.; Tse, E. C. M.; Rauchfuss, T. B.; Gewirth, A. A. Ligand Effects on the Overpotential for Dioxygen Reduction by Tris(2-Pyridylmethyl)Amine Derivatives. Inorg. Chem. 2013, 52 (2), 628-634. https://doi.org/10.1021/ic301656x.

(36) Wang, F.-F.; Zhao, Y.-M.; Wei, P.-J.; Zhang, Q.-L.; Liu, J.-G. Efficient Electrocatalytic O2 Reduction at Copper Complexes Grafted onto Polyvinylimidazole Coated Carbon Nanotubes. Chem. Commun. 2017, 53 (9), 1514-1517. https://doi.org/10.1039/C6CC08552K.

(37) McCrory, C. C. L.; Ottenwaelder, X.; Stack, T. D. P.; Chidsey, C. E. D. Kinetic and Mechanistic Studies of the Electrocatalytic Reduction of $\mathrm{O} 2$ to $\mathrm{H} 2 \mathrm{O}$ with Mononuclear $\mathrm{Cu}$ Complexes of Substituted 1,10-Phenanthrolines. J. Phys. Chem. A 2007, 111 (49), 1264112650. https://doi.org/10.1021/jp076106z.

(38) Slowinski, K.; Kublik, Z.; Bilewicz, R.; Pietraszkiewicz, M. Electrocatalysis of Oxygen Reduction by a Copper(II) Hexaazamacrocyclic Complex. J. Chem. Soc., Chem. Commun. 1994, No. 9, 1087-1088. 